\title{
Sociocultural behavioral traits in modelling the prediction of COVID-19 infection rates
}

\author{
Charles Alba \\ Student Engagement Network, The Pennsylvania State University, \\ University Park, PA, USA, and \\ Manasvi M. Mittal \\ College of Information, Sciences and Technology, \\ The Pennsylvania State University, University Park, PA, USA
}

\section{Sociocultural behavioral traits}

Received 12 August 2021 Revised 31 August 2021 Accepted 31 August 2021

\begin{abstract}
Purpose - Over the past decades, many health authorities and public policy experts have traditionally relied on indicators that are dependent on a nation's economy, its health-care infrastructure advancements, and superiority in biomedical sciences and technology to predict potential infection rates should a health pandemic occur. One such commonly relied-upon indicator was that of the Global Health Security (GHS) Index. However, the coronavirus disease 2019 (COVID-19) pandemic has shown how such variables prove to be inaccurate in predicting the infection rates during a global health pandemic. Hence, this paper proposes the utilization of socio-cultural behavioral traits to predict a country's COVID-19 infection rates.

Design/methodology/approach - This is achieved by proposing a model involving the classification and regression tree (CART) algorithm and a Poisson regression against the six selected cultural behavioral predictors consisting of individualism, power distance, masculinity, uncertainty avoidance, long-term orientation, and indulgence.

Findings - The results show that all the selected cultural behavioral predictors are significant in impacting COVID-19 infection rates. Furthermore, the model outperforms the conventional GHS Index model based on a means squared error comparison.

Research limitations/implications - The authors hope that this study would continue promoting the use of cultures and behaviors in modeling the spread of health diseases.

Practical implications - The authors hope that their works could prove beneficial to public office holders, as well as health experts working in health facilities, in better predicting potential outcomes during a health pandemic, thus allowing them to plan and allocate resources efficiently.
\end{abstract}

(C) Charles Alba and Manasvi M. Mittal. Published in Journal of Humanities and Applied Social Sciences. Published by Emerald Publishing Limited. This article is published under the Creative Commons Attribution (CC BY 4.0) licence. Anyone may reproduce, distribute, translate and create derivative works of this article (for both commercial and non-commercial purposes), subject to full attribution to the original publication and authors. The full terms of this licence may be seen at http:// creativecommons.org/licences/by/4.0/legalcode

The authors would like to thank Prof James Wang (PhD., MSc., MSc.) and Mr. Li Yu (Msc.) for this opportunity, and more importantly, for their close guidance and helpful advice throughout this whole process. The authors would also like to acknowledge Ms. Anmolika Singh, who helped conceptualized the idea, but was not involved in the pipeline of the project. The authors would also like to thank the researchers of the 2021 Undergraduate Exhibition (Social and Behavioral Science) who provided us valuable feedback during the presentation of the preliminary methods and results presentation (Alba et al., 2021).

Funding: This project was funded by the Pennsylvania State University's Student Engagement Network Remote Innovation Grant (Grant number 012599).

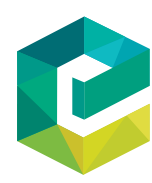

Journal of Humanities and Applied Social Sciences
Vol. 3 No. 5,2021 pp. $339-355$ pp. 339-355
Emerald Publishing Limited 2632-279X DOI 10.1108/JHASS-07-2021-0128 
JHASS
3,5

340

Originality/value - The results are a testament to the fact that sociocultural behavioral traits are more reliant predictors in modeling cross-national infection rates of global health pandemics, like that of COVID-19, as compared to economic-centric indicators.

Keywords Health policy, COVID-19, Cultures, Sociocultural behaviors

Paper type Research paper

\section{Introduction}

For the longest time, authorities, researchers, and planners at a local, national, and global level have heavily relied on indicators that are a function of a nation's economic stability and its advances in health-care infrastructure and technology to predict the spread of viruses during a global health pandemic. Hence, these metrics were crucial in assessing their preparations concerning global health pandemics. Their initial assessments based on these metrics are critical in amending relevant policies to best prepare their communities for global health pandemics (McInnes and Lee, 2006; Rushton and Youde, 2014). Such is demonstrated by existing metrics such as that of the Global Health Security (GHS) Index (Rushton, 2011; Boyd et al., 2020), which relies on a series of nonbehavioral variables to matriculate its data (Razavi et al., 2020). Such nonbehavioral variables include a country's health-care infrastructure capacity, its advances in biomedical sciences and technology, and its overall economic and political stability (Razavi et al., 2020). Even recently recommended metrics such as that of the Epidemic Preparedness Index do heavily weigh a "country's economic resources, public health communications, infrastructure, public health systems, and institutional capacity" in its metric evaluation (Oppenheim et al., 2019). However, as evidently shown in the figures in relation to the coronavirus disease 2019 (COVID-19) pandemic (like that of Figure 1), indexes like that of the GHS Index have come under scrutiny from medical or health-care experts as well as public policy experts alike for its failure toward coming remotely close to predicting or forecasting the real figures of the COVID-19 pandemic (Aitken et al., 2020; Abbey et al., 2020). We would discuss this more in Section 1.2. This has led many to question the viability of such metrics for future uses (Aitken et al., 2020; Abbey et al., 2020; Dalglish, 2020).

Figure 1. Total COVID-19 cases as of August 2021

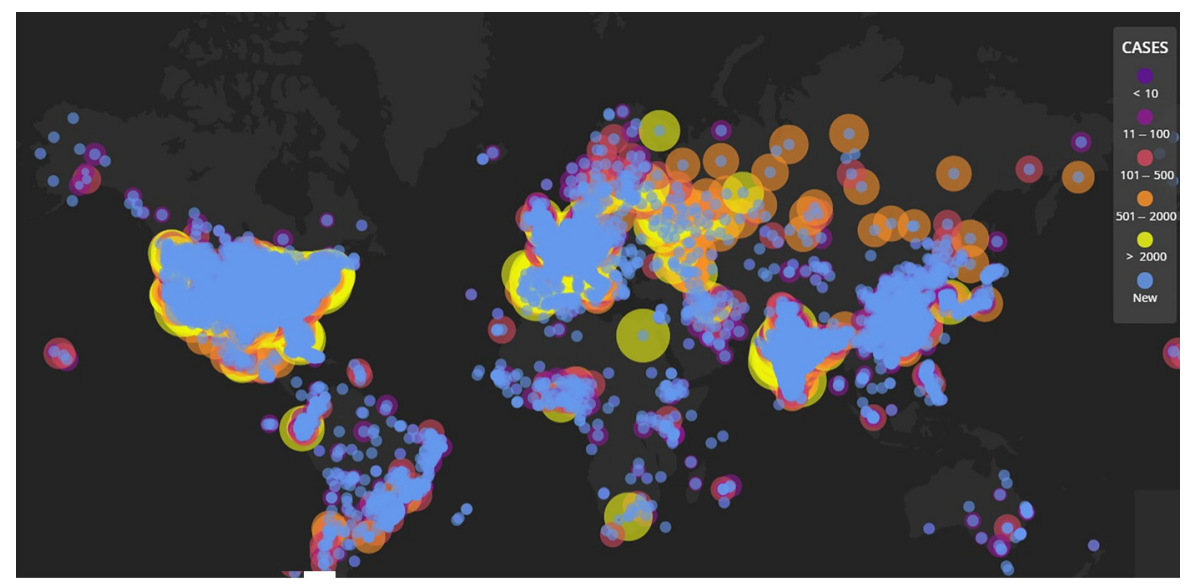

Source: Xu et al, 2021 


\subsection{Purpose}

Many metrics have often neglected the behavioral aspects of a pandemic. However, as evidently displayed by the COVID-19 pandemic, we have witnessed how the behavioral traits spanning across different countries do impact its COVID-19 infection rates. This could be attributed to the fact that global health pandemics are infectious, and therefore one's behavior could directly infect and impact its infection rates (Soofi et al., 2020). This would be elaborated in Section 1.3. Thus, we propose the use of numerous quantifiable behavioral traits to predict a country's COVID-19 infection rates. Specifically, we have identified six

distinct sociocultural behavioral traits as predictors. These six traits are individualism, power distance, masculinity, uncertainty avoidance, long-term orientation, and indulgence, and would be elaborated in Section 2.

Because the GHS Index was traditionally considered the "Bible" of models in predicting global health pandemics prior to COVID-19, we shall use the GHS model as a form of comparison to our proposed model in this paper.

\subsection{Failure of the GHS Index}

The Index is scored on a zero- to hundred-point scale, with 100 representing the highest possible score a country can receive. However, although the Index is useful in identifying gaps in pandemic preparedness, the GHS Index rankings and scores are not correlated with COVID-19 infection rates (Nuzzo et al., 2020).

Furthermore, while economic indicators could potentially be used to suppress novel viruses through the development of vaccines, it fails to account for the crucial time lag between the initial spread of the virus until the time it takes to effectively vaccinate communities to a level in which herd immunity is achieved.

The initial spread of the virus is arguably as critical as the development of a vaccine (Karaivanov et al., 2021; Howard et al., 2021). A nation that is able to keep the spread of novel viruses under control during a health pandemic would be able to prevent deaths and swiftly converge back to a "normal life", thus requiring less effort or urgency in achieving herd immunity amongst its communities through methods like vaccinations (Mazey and Richardson, 2020).

This is evident from comparing the COVID-19 infection rates of Figure 1 with the GHS Index of Figure 2. These maps are exemplary of how countries that were deemed the most prepared in terms of a global health pandemic fared the worst, while the exact opposite happened to countries that were slated to be the least prepared toward a global health pandemic. For instance, the USA which was ranked as the "most prepared" country to deal with a GHS threat by the GHS Index has witnessed the highest cases of COVID-19 infection rates, while countries like Vietnam which rank 50 in the GHS Index have been highly praised for its handling of the COVID-19 pandemic (Duong et al., 2020). This has led many to question the viability of such metrics for future uses (Aitken et al., 2020; Abbey et al., 2020; Dalglish, 2020).

\subsection{How behaviors could affect COVID-19 and why it could be a good predictor}

Keeping the spread of novel viruses, like that of COVID-19, within control is critical in the initial stages of a pandemic whilst waiting months or potentially years for a vaccine to develop (Black et al., 2020). Unlike economic indicators which fail to account for the massive time-lag between the spread of a novel virus to the immunization of its population, behavior does have a direct and immediate impact on the spread of any virus. Furthermore, most global health pandemics are known to be extremely contagious (Honigsbaum, 2009; Morens et al., 2009) and are, therefore, more susceptible to massive or rapid spreads. In the instance 


\section{JHASS 3,5}

\section{2}

Figure 2.

The GHS Index

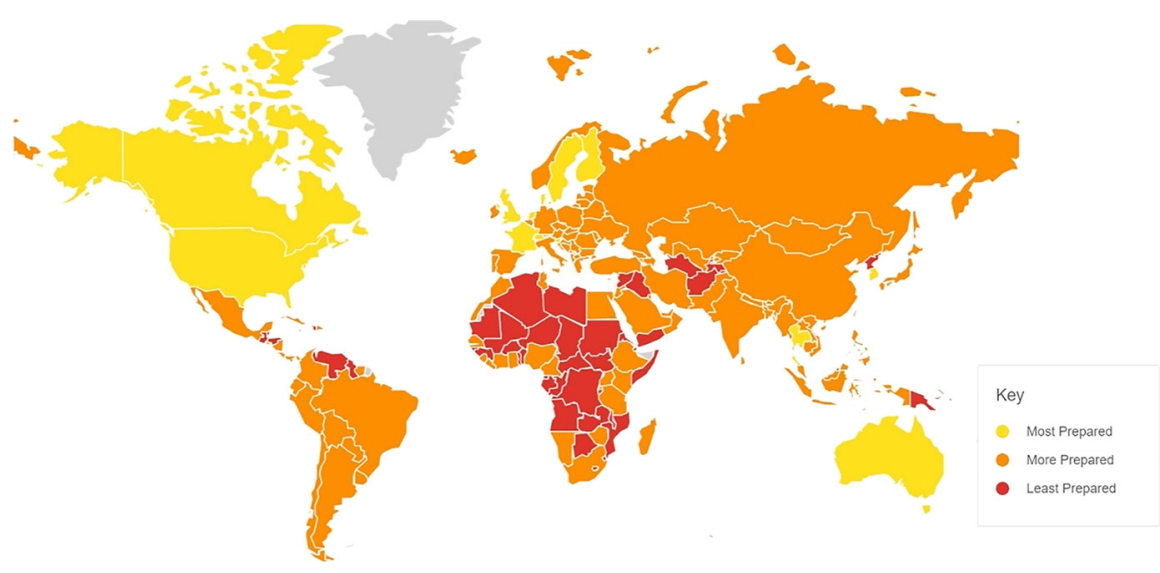

Source: Cameron, 2020

of COVID-19, the virus is known to spread through infected droplets/fluids (Chaudhuri et al., 2020; World Health Organization, 2020), with studies suggesting that the virus is potentially airborne (Borak, 2020; Setti et al., 2020). Therefore, behavior is important to control the spread of contagious novel health viruses and keep their surroundings safe. Behavior could include wearing a mask in public, sanitizing hands regularly, keeping social distance, etc. Maintaining behavior to spread fewer water droplets is important and responsible for society which not everyone follows.

For instance, according to Galbadage et al. (2020), social distancing is an evidence-based practice to help prevent the transmission of pathogens that are known to spread from person to person within a $3-6$ feet distance through respiratory droplets. The adherence to social distancing is henceforth reliant on culturally dependent behavioral traits as is made evident by Durante et al. (2021), Huynh (2020) and Nikolov et al. (2020).

Another widely studied field correlates behavior to the adherence of mask-wearing. While it is widely proved that mask-wearing does help prevent the spread of COVID-19 between individuals, the adherence to mask mandates has remained a pressing issue since the start of the pandemic. Many social scientists have suggested that such behaviors are attributed to sociocultural behavioral traits (He et al., 2021; Hearne and Niño, 2021; Palmer and Peterson, 2020; Nikolov et al., 2020), with Palmer and Peterson (2020) even specifying masculinity, which is one of our predictors, as an influential trait that influences such mask defying behavior.

Therefore, it normatively seems fitting to use behavioral indicators in favor of economiccentric indicators in the prediction of novel viruses, like that of COVID-19, for it directly and instantly accounts for the spread of viruses within communities.

\subsection{Who would benefit from it?}

This proposed model could be useful in evaluating a country's preparedness for future health crises or health pandemics.

Thus, from a macro-perspective, our paper is targeted toward health policy experts, public policy experts, sociological psychologists and public office holders or appointees. Specifically, they could assess or predict potential outcomes or preparedness toward future health pandemics based on their numerous sociocultural behavioral traits. Based on such 
predictions, they could then craft policies or legislature and allocate the appropriate funds aimed at improving their chances of better preparing for future health crises (Murray and Frenk, 2008; Gadarian et al., 2021; Jay and Paulo, 2020).

From a micro-perspective, health providers, hospital staff and manufacturers of essential health-care equipment could also benefit greatly from such findings. Specifically, they could use such findings to prepare, anticipate or stand by the necessary equipment like makeshift beds and personal protective equipment (PPE) like $N 95$ masks, waterproof gowns and faceshields (Amrami et al., 2021).

Sociocultural behavioral traits

\subsection{Related works}

What makes our work novel is the fact that no existing known literature has attempted to use quantifiable behavioral traits to model cross-national COVID-19 infection rates at a global scale. While there is existing literature targeted toward correlating quantifiable behaviors to that of COVID-19, most of these studies in the literature are aimed at using behavior to predict specific reactions to peculiar micro-aspects of COVID-19. For instance, a study done by Margraf et al. (2020) examined the behavioral traits of "perceived usefulness, adherence and their predictors" to explain reactions and outcomes related to mask-wearing and social distancing. This study was limited to only eight countries. Other attempts in using behaviors to predict COVID-19-related incidents include the utilization of Twitter analytics to explain the opposition toward mask-adherence (He et al., 2021), using socioeconomic factors to analyze the adherence toward mask-wearing mandates (Hearne and Nino, 2021), and attempting to correlate mask-adherence defiance to socialcultural behavioral traits like masculinity (Palmer and Peterson, 2020).

The spread of fake news relating to COVID-19 remains another widely published domain that attempts to link behavior to aspects concerning COVID-19. For instance, van der Linden et al. (2020), as well as Rodrigues and Xu (2020) have attempted to correlate behaviors with the spread of fake news relating to COVID-19, with the ultimate goal of using these findings to mitigate the spread of COVID-19 misinformation.

While these publications fall within the same broad umbrella of using behaviors to explain COVID-19 outcomes, it extensively differs from our aim of using sociocultural behavioral traits to model the prediction of cross-national spread of health pandemics like that of COVID-19.

\section{Description of the identified cultural behavioral traits}

The six identified behavioral traits that have been identified include individualism, power distance, masculinity, uncertainty avoidance, long-term orientation and indulgence. They are commonly known as the "dimensions of national culture" (Hofstede, 2011). These traits are selected because they have been identified as traits by socio-psychologists as behavioral traits that can be spanned and identified uniquely across national boundaries (Hofstede et al., 2005; Minkov, 2007).

The first four traits were first matriculated by Hofstede (Hofstede et al., 2005) and the latter two were later built upon Hofstede's works by Minkov (2007). All these behavioral traits for our selected data source are scored based on a 0 to 100 scale.

While there are many multidimensional models (Minkov and Kaasa, 2021; House et al., 2004; Bond and Lun, 2014; Leung et al., 2002; Inglehart and Baker, 2000; Stankov et al., 2014; etc.) which we could rely on for our analysis, we selected the model by Minkov et al. (2016) since many of these models are derived and originated from aspects of the model proposed by Hofstede and Minkov. This originality could also reduce the phenomena of multicollinearity and the curse of dimensionality - as many of the models extract multiple 


\section{JHASS 3,5}

dimensions in their same proposed framework from singular dimensions of Hofstede's (1991) work. Thus, choosing the updated but original works of Minkov et al. (2016) where the dimensions were crafted with individuality could add legitimacy toward our model from reduced multicollinearity, as later exemplified in Section 4.2.

Furthermore, this remains the only model that contains comprehensive vast global records that have been recorded and updated since its inception by Hofstede (1991). Furthermore, it remains the only model to have comprehensive validation between its subjective cultural theories and objective cultural applications (Minkov and Kassa, 2021).

Finally, with relevance to the previously mentioned point, this selected model by Minkov et al. (2016) remains one of the few models which is behavioral or socioeconomical in nature, rather than philosophical or classical in nature. This makes it more applicable for our study of the influence of the spread of viruses through human behavior.

\subsection{Individualism}

Individualism is a social pattern that "consists of individuals who view themselves as independent of any community" (Triandis, 2018). Thus, they are primarily motivated by their personal goals and desires (Triandis, 2018; Hofstede, 2011). Individualistic cultures are typically affiliated with national characteristics of freedom, assertiveness and universalism (Minkov and Kaasa, 2021). Collectivism, on the other end of the spectrum in the "individualism dimension", could be best described as "the social pattern consisting closely linked individuals who see themselves as part of one or more collectives" (Triandis, 2018). Such collectives could refer to groups within their communities such as families, work employees or tribes. Thus, from a behavioral perspective, individuals from nations with more collective cultures tend to focus on the goals of these collectives over their personal goals (Triandis, 2018; Hofstede, 2011) due to their prioritization of social factors (Mahrous, 2011). Cultural traits are often correlated with national characteristics of conformism, submissiveness and exclusionism (Minkov and Kaasa, 2021). Therefore, a country that was the most individualistic culture would obtain a score of 100 , whereas a country with a collectivist culture would obtain a score of 0 .

\subsection{Power distance}

Power distance "refers to the extent to which national cultures expect and accept that power is distributed unequally in society" (Basabe and Ros, 2005; Mahrous, 2011). Thus, countries that score higher in their power index rankings could expect a culture whereby their citizens expect or command formal deference to higher authorities (e.g. parents or elected officials) compared to their counterparts with lower power index score (Basabe and Ros, 2005; Hofstede, 2009). Thus, while countries with higher power distance indexes are expected to witness lower levels of power inequality, they are expected to resent big powerful groups like governments or large corporate entities compared to their counterparts with lower power index scores (Mahrous, 2011).

\subsection{Masculinity}

Countries that score highly on the Masculinity Index are known to be more "masculine" in the sense whereby they are expected to align with the more "historical and outdated" perspective of the roles of men and women whereby "men are (expected) to be assertive, ambitious and competitive (and) to strive for material success" (Arrindell et al., 2003; Hofstede, 1984, 1986, 1996), whereas "Women are expected to serve and care for the nonmaterial quality of life, for children and for the weak" (Arrindell et al., 2003; Hofstede, 1984, 1986, 1996). Thus, more masculine societies are expected to have a greater emphasis 
on material success over other value-based nonmaterialistic issues (Mahrous, 2011). Countries that score lower on this index thus identify with a more feminine perspective, whereby women and men could have more overlapping and equal societal responsibilities (Arrindell et al., 2003; Hofstede, 1984, 1986, 1996).

\subsection{Uncertainty avoidance}

Uncertainty avoidance pertains to distrust and anxiety its relevant citizens would face when confronting unknown situations. Thus, a country where its citizens are expected to face distrust and anxiety in the face of unknown adversaries, like that of the COVID-19 pandemic would score higher in the uncertainty avoidance index. As a result, countries with higher uncertainty avoidance are expected to witness higher levels of stress and anxiety compared to their more uncertainty tolerant counterparts. Conversely, countries that are uncertainty tolerant, the opposite of uncertainty avoidance, are more likely to confront unknown situations with "fixed habits and rituals", all in pursuit of the truth (Steinhauser, 2018; Hofstede, 2009).

\subsection{Long-term orientation}

In a long-term-oriented culture, also known as Flexhumility, its citizens are expected to display foresight by planning for the future as always needed. Thus, a country where its citizens are viewed as more long-term oriented is expected to score high in the long-term orientation index (Kapros, 2019). Thus, flexhumility societies are frequently affiliated with national values of self-control and self-sufficiency. On the other hand, countries with shortterm-oriented cultures do not necessarily lack foresight, rather, they simply believe that the "past provides a moral compass" (Alcantara-Pilar et al., 2018) and they are thus expected to adhere to their moral compasses as a form of moral good whilst living in the present (Alcantara-Pilar et al., 2018). This is also known as monumentalism. Hence, monumentalistic societies often observe high self-esteem (Minkov and Kassa, 2021) and self-content (Minkov and Kassa, 2021). This index is meant to reflect a more philosophical and religious aspect of a country's behavior rather than the practical side of a country's behavior (Minkov, 2007).

\subsection{Indulgence}

In countries that score high on the "indulgence" index, individuals are expected to engage in impulses that satisfy their wants and feelings. Henceforth, society must feel free and "easygoing". On the other hand, countries that score low on the "indulgence" index are said to be more restrained, whereby their citizens feel that life is tough, dominated by duties and is filled with restricted amounts of freedom (Iancu and Badea, 2020).

\section{Research methodology}

3.1 Data collection and materials

3.1.1 COVID-19 data. We obtain our up-to-date COVID data courtesy of Ritchie from the European Center for Disease and Prevention control (Ritchie, 2020). It is worth noting that we count and consider our COVID cases $C_{i}$ with respect to time $t_{i}$ which is the time difference in days from which the first case(s) of COVID was reported in $i$ th country up to Dec 14, 2020 (Hubbard, 2020; Elbaum, 2020). We chose Dec 14, 2020 as our cutoff because it was the date a vaccine was approved. Thus, we chose this date wanting to avoid potential confounding variables from impacting our analysis, because after all, in a pandemic, a country's citizens' reaction to the approval of the vaccine can be correlated with both its infection rates and behavior.

3.1.2 Behavioral data. Our behavioral data of the six distinct quantified behavioral traits identified and explained in Section 2 was accurate as of 2016 (Hofstede, 2016). This
Sociocultural behavioral traits 
JHASS

3,5

\section{6}

dataset presents us with $n=97$ countries worth of relevant behavioral data. It is worth noting that some countries had missing data from some behavioral traits. Thus, we have decided to use classification and regression tree (CART) imputation, to "fill in" these missing data. This would be elaborated in Section 3.2.

Thus, in total we have $n=97$ countries as our sample size after merging the two distinct datasets.

\subsection{Methods}

Hence, we would use the following algorithm to proceed with our implementation:

(1) Apply the CART algorithm to impute the missing data.

(2) Use Poisson regression to analyze our data.

3.2.1 CART imputation We use the CART algorithm to impute our missing behavioral data, as elaborated and exemplified by Van Buuren et al. (2018). Our obtained bootstrap of $\left(Y_{o b s}, X_{o b s}\right)$ is set to size $n_{1}=50$.

3.2.2 Poisson regression. We will use a Poisson distribution, where:

$$
r_{i} \sim \operatorname{Pois}\left(\lambda_{i}\right)
$$

where:

$$
r_{i}=\left(\frac{c_{i}}{p_{i}}\right) * 1000000
$$

and

$$
\lambda_{i}=\frac{c_{i}}{t_{i}}
$$

given $C_{i}$ is the number of cases for given country $i, t_{i}$ is the time-period in terms of the number of days since COVID-19 was first confirmed in $i$ th country up to Dec 14 (the day a COVID vaccine was approved), $p_{i}$ is the population of $i$ th location. Thus, this will prompt us to obtain the following:

$$
\log \left(\frac{\lambda}{p} * 1000000\right)=\beta_{0}+\beta_{1} X_{1}+\ldots+\beta_{n} X_{n}
$$

thus, giving us:

$$
\log (\lambda)=\beta_{0}+\beta_{1} X_{1}+\ldots+\beta_{n} X_{n}+\log \left(\frac{p}{1000000}\right)
$$

where $X_{n}$ is the given $n=1,2,3,4,5,6$ denoting each distinct behavioral index previously identified in Section 2.

\section{Results}

\subsection{Data analysis}

As shown in Figure 3, the individualism (sub Figure 3a), power distance (sub Figure 3b), uncertainty avoidance (sub Figure 3d), long-term orientation (sub Figure 3e) and indulgence (sub Figure 3f) indexes displayed positive correlations with the COVID cases per million population, denoted as $r_{i}$ in Eqn (2). Only the masculinity index (Sub Figure 3c) displayed a negative correlation with the COVID cases per million population. 


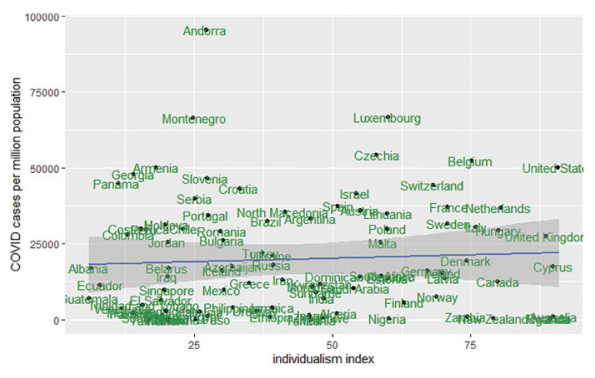

Individualism index against covid cases per million population $r_{i}$

(a)

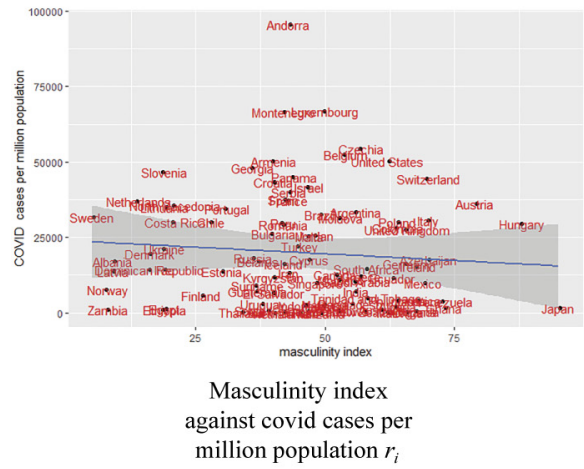

(c)

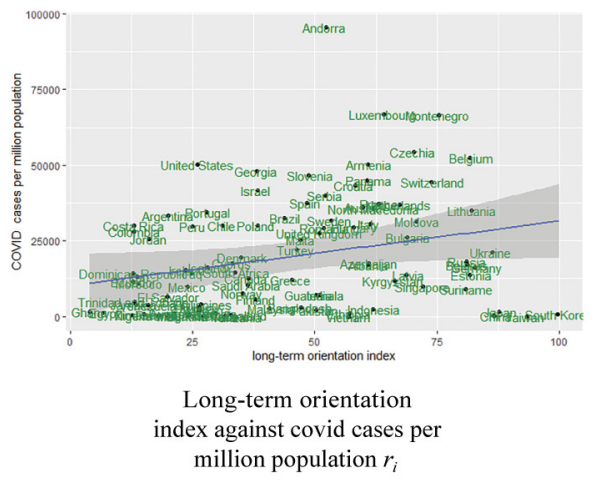

(e)

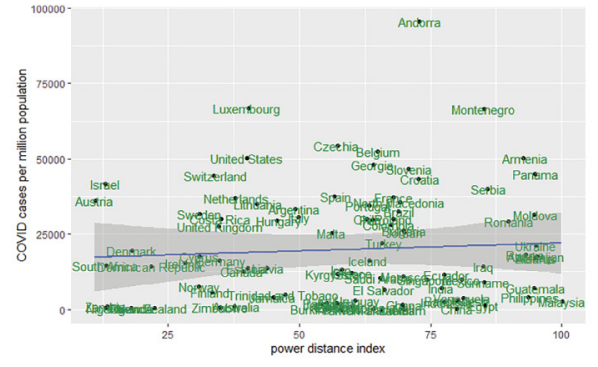

Power Distance index against covid cases per million population $r_{i}$

(b)

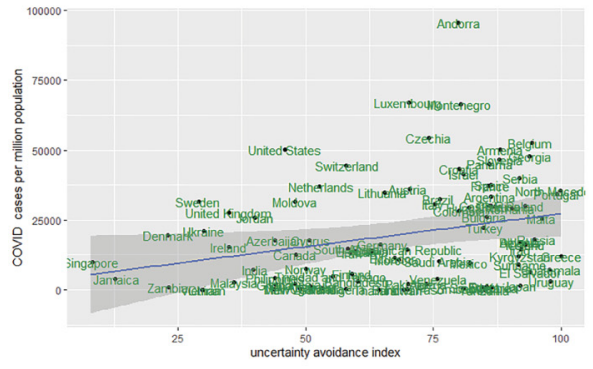

Uncertainty Avoidance index against covid cases per million population $r_{i}$

(d)

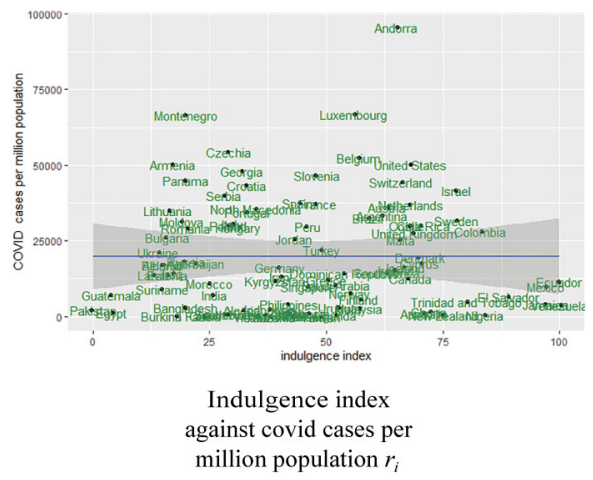

(f)
Sociocultural behavioral traits
Figure 3.

The respective individual behavioral indexes against the COVID cases per million population $\left(r_{i}\right)$

\subsection{Statistical findings}

The obtained statistical results in Table 1 suggest that at $\alpha=0.001$ we have very strong evidence to suggest that the six identified behavioral traits have a significant impact on a country's COVID-19 infection rates given $p$-value $<\alpha$. 
JHASS

3,5

\section{8}

Furthermore, the fact that our Variance Inflation Factor (VIF) falls within the reasonable range of $\mathrm{VIF}<3$ amongst all the variables suggests that the identified behavioral traits remain uniquely distinctive across different nations.

\subsection{Machine learning outcomes}

In comparison to the GHS model, our proposed model outperforms the GHS model by Mean Square Error's (MSE) comparison of MSE $=3307.668$ for parameter $\lambda$ based on a 70-30 train-test split, as best illustrated in Figure 4.

It is worth noting that the GHS model has predicted a country's preparedness and ability to handle the pandemic in the opposite direction to the actual happenings of the COVID-19 pandemic in terms of the number of COVID infection rates per million population (denoted $r_{i}$ ). This was previously discussed in Section 1.2.

However, even if we were to ignore this facet and run a fitted GHS model against a country's COVID-19 infection rates, our behavioral model in Eqn (5) still outperforms this model by MSE $=1461.748$ in a 70-30 train-test split.

These results are further evidence of our hypothesis that these behavioral indexes are indeed an accurate and reliable indicator toward the spread of an infectious disease during a global health pandemic.

\section{Discussion}

\subsection{Model accuracy and reliability}

Our results show that our selected sociocultural behavioral traits are more accurate predictors in modeling the spread of viruses, like COVID-19, as compared to indicators that

\begin{tabular}{|c|c|c|c|}
\hline Coefficients & Estimate & $Z$-value & $\operatorname{Pr}(>|z|)$ \\
\hline (Intercept) & -0.6533763 & -32.75 & $<2 * 10^{-16} * * * *$ \\
\hline Power distance & 0.0205647 & 129.22 & $<2 * 10^{-16} * * *$ \\
\hline Individualism & 0.0394228 & 311.16 & $<2 * 10^{-16} * * *$ \\
\hline Masculinity & -0.0142707 & -92.55 & $<2 * 10^{-16} * * *$ \\
\hline Uncertainty avoidance & 0.0217409 & 191.78 & $<2 * 10^{-16} * * *$ \\
\hline Long-term orientation & -0.0046719 & -39.98 & $<2 * 10^{-16} * * *$ \\
\hline Indulgence & 0.0156474 & 124.72 & $<2 * 10^{-16} * * *$ \\
\hline
\end{tabular}

Table 1.

Statistical results based on the model in Eqn (5)

Notes: $* * * 0.001 ; * * 0.01 ; * 0.05 .0 .1$

Figure 4.

Comparisons of models

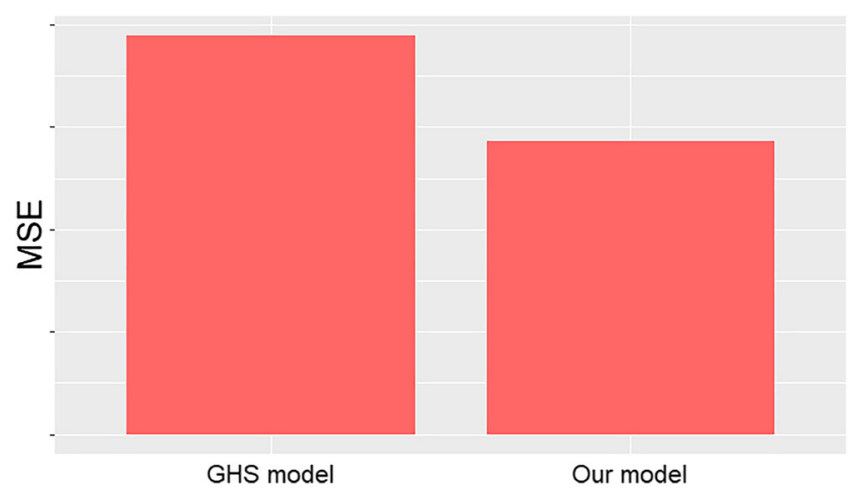


are dependent on a country's economic strength and advancements in biotechnology, like the GHS Index. Thus, we hope that this spearheads the use of quantifiable behavioral traits in predicting the spread of novel health pandemics at a cross-national level.

\subsection{Policy implications}

5.2.1 Policy implications toward stakeholders involved at a macro-level. From the macroperspective, these results could certainly shift the mindsets of stakeholders involved at a macro-level, as previously elaborated in Section 1.4. Public and health policy office holders should be encouraged by our results to consider the behavioral aspects when crafting measures to deal with health pandemics. Policies should be legislated with the consideration of how its citizens would behave. Furthermore, specific guidelines should be drafted with the goal of counteracting the negative aspects of our selected sociocultural behavioral predictors while enhancing the positive aspects of our chosen predictors.

This mindset of legislating pandemic-oriented policies largely differs from traditional mindsets attributed by traditional economic-centric indicators like that of the GHS Index. Specifically, prior to the COVID-19 crisis, policy-makers crafted pandemic-oriented policies by seeking to assess and advance their health-care technologies or biomedical advancements. The perception behind this is that a society with a stronger economic status is able to invest more in health-care technologies that could better deal with the outbreak of viruses. This perception is certainly encouraged by indicators like the GHS Index which has ranked a country's preparedness solely on economic-centric indicators. However, as suggested from our results and based on our explanations in Section 4.2, this mindset is evidently flawed. Thus, we hope that our results could encourage a shift in mindsets of stakeholders involved in a macro-level, where behavioral traits are considered in favor of economic statuses to keep future global health pandemics under control.

For instance, our results show that countries that are ranked higher in terms of individualism tend to have higher COVID-19 infection rates. This means that societies with individuals who tend to view themselves as independent stakeholders of their community are likely to fare poorer in initial responses to the breakouts of global health pandemics. Hence, with that in mind, health authorities governing countries with higher individualism index scores could consider the fact that should a health pandemic occur, individuals are more likely to fend for themselves or their immediate loved ones and contribute or rely less on the community for help. Hence, policies like the distribution of stimulus cheques could prove effective, as more "individualistic" individuals are more likely to risk going out to work to financially support their loved ones, and less likely to have structural support from their communities. Likewise, when advertising mandates like stay-home orders or mask mandates, public policy officials governing more individualistic societies could perhaps consider advertisements that place a heavier emphasis on the immediate impacts on individuals and their loved ones instead of reiterating the safety of communities.

Using uncertainty avoidance as another instance, our results show that countries with higher scores in this index (i.e. are more avoiding) naturally fare better in controlling the spread of pandemics than countries with more "tolerant" individuals.

This means that societies with individuals who are not anxiously deterred by the unknown or uncertainty of information are more likely to fare poorer as compared to their more "uncertain" counterparts. Hence, countries that score lower in this index (i.e. are more tolerant), may want to reconsider being precautious or reserved in communicating findings or information during the breakout of novel viruses simply because their citizens are not deterred from the unknown. Federal authorities in such intolerant societies may also want to reconsider introducing executive enforcements or overriding local governments, especially
Sociocultural behavioral traits 
JHASS 3,5

pertaining guidelines and regulations. This is because they are likely to embrace such clearly written rules and regulations from the highest of authorities as compared to their more "uncertain" counterparts (Mahrous, 2011).

It is worth noting that the two above examples are not meant to be exhaustive, but serve as an exemplification of how our results cause a fundamental shift in the mindsets when dealing with global health pandemics.

5.2.2 Policy implications toward stakeholders at a micro level. Our model could also better aid stakeholders, like hospital staff and manufacturers of PPE equipment, as previously elaborated in Section 1.4. Specifically, our model gives us an insight into the impact of sociocultural behavioral traits on the spread of diseases like COVID-19 as elaborated in our results. Thus, the aforementioned stakeholders could now better anticipate the reactions concerning a health pandemic. These stakeholders could henceforth ensure a more equitable allocation of resources when dealing with global pandemics.

For instance, our results show that countries that are ranked higher in terms of individualism tend to have higher COVID-19 infection rates. Thus, as elaborated in Section 2, more individualistic societies, where its citizens tend to see themselves as individuals and thus fend for themselves in times of crisis, are more likely to fare poorer in global pandemics. Thus, one would expect individuals from more individualistic societies to buy massive amounts of supplies like PPE out of immediate concern for themselves or their loved ones. This behavior of "panic buying" was common in countries like the USA (Shanthakumar et al., 2020) and the United Kingdom (Bentall et al., 2021), which scored higher in the individualism index. Hence, stakeholders like manufacturers of PPE could utilize our model in determining potential reactions to phenomena like panic-buying by imposing restrictions or quotas on the purchase of supplies.

This example is not meant to be exhaustive but serves as a demonstration of how our model could potentially benefit stakeholders at a micro level, as previously elaborated in Section 1.4.

\section{Conclusion}

We proposed the use of numerous quantifiable sociocultural behavioral traits in modeling the prediction of a country's COVID-19 infection rates. Our model involves the use of the CART imputation algorithm and Poisson regression. Our results show that the six identified sociocultural behavioral traits of individualism, power distance, masculinity, uncertainty avoidance, long-term orientation and indulgence have a very significant impact in predicting a country's COVID-19 infection rate. Likewise, our proposed model outperforms the GHS Index model, which is heavily reliant on economiccentric indicators and indicators that are reflective of a country's advancements in healthcare or biotechnology.

\subsection{Limitations and future works}

As evident from this paper, this paper is focused on predicting a country's COVID-19 infection rates. As such, it is obvious that it fails to account for variations and differences in COVID-19 infection rates within each respective nation. This limitation can be attributed to the fact that our selected version of Minkov and Hofstede's behavioral traits are meant to be distinctive across nations, and thus, such data are not available at an interstate, intercity or intercommunity level. After all, as best noted by both Hofstede (1996, 1984, 2009, 2016) and Minkov (Minkov and Kaasa, 2021), as well as other established researchers (House et al., 2004; Lenartowicz and Roth, 2001; Tung, 2008; 
Mahrous, 2011), such distinctive behavioral cultures drawn within national boundaries are not meant to reflect intercultural traits.

In terms of future works for similar studies at an interstate level, Minov and Kaasa (2021) recently introduced a "revised" version of their "model of cultures" involving the 50 US states which include a singular cultural metric identified as the "subjective-culture individualism-collectivism" dimension.

However, this availability remains limited only in the context of the USA. Furthermore, this involved a different methodology as compared to our proposed model which was done in the global context.

In terms of future works for similar studies at an intercity and intercommunity level, there are plentiful amounts of the literature directed toward structuring matriculated and quantifiable behaviors at a community level (Glenwick and Jason, 1984; Jason et al., 2021). Psychologists often refer to this as behavioral community psychology.

Unfortunately, most of these metrics require heavily involved interactions with communities, which was not possible at the given time of this written work, due to enforced measures like social distancing required to suppress COVID-19.

Thus, if any future work should be done on our works, we hope it could be focused on using such methods aimed at applying quantifiable behavioral traits in predicting COVID-19 or health pandemic infection rates at a state, city or community level.

\section{References}

Abbey, E.J., Khalifa, B.A., Oduwole, M.O., Ayeh, S.K., Nudotor, R.D., Salia, E.L., Lasisi, O., Bennett, S., Yusuf, H.E., Agwu, A.L. and Sic Karakousis, P.C. (2020), "The global health security index is not predictive of coronavirus pandemic responses among organization for economic cooperation and development countries", PloS One, Vol. 15 No. 10, p. e0239398.

Aitken, T., Chin, K.L., Liew, D. and Ofori-Asenso, R. (2020), "Rethinking pandemic preparation: global health security index (ghsi) is predictive of covid-19 burden, but in the opposite direction", The Journal of Infection, Vol. 81 No. 2, p. 318.

Alba, C., Mittal, M. and Singh, A. (2021), "Using quantifiable behavioral traits to predict a country's covid 19 infection rates", 2021 Undergraduate Exhibition (Social and Behavioral Sciences), 16095.

Alcantara-Pilar, J.M., Del Barrio-Garcia, S. and Rodrıguez-L“opez, M.E. (2018), "Does language matter? a cross-national comparison of the moderating effect of language on website informationprocessing", Journal of Business Research, Vol. 88, pp. 66-78.

Amrami, K., Domnick, R., Heinzen, E., Helfinstine, K., Jayakumar, A., Johnson, P., Knepper, C., Marcelletti, D., Mickelson, M., Rojas, R., George, M.S., Tande, A., Walvatne, K., Wutthisirisart, P., Pollock, B.D., Carter, R.E., Dowdy, S.C., Dunlay, S.M., Habermann, E.B., Kor, D.J., Limper, A. H., Liu, H., Franco, P.M., Neville, M.R., Noe, K.H., Poe, J.D., Sampathkumar, P., Storlie, C.B., Ting, H.H. and Shah, N.D. (2021), "Deployment of an interdisciplinary predictive analytics task force to inform hospital operational decision-making during the covid-19 pandemic", Mayo Clinic Proceedings, Elsevier, Vol. 96, pp. 690-698.

Arrindell, W.A., Eisemann, M., Richter, J., Oei, T.P., Caballo, V.E., Van der Ende, J., Sanavio, E., Bag“es, N., Feldman, L., Torres, B., et al. (2003), "Masculinity-femininity as a national characteristic and its relationship with national agoraphobic fear levels: fodor's sex role hypothesis revitalized", Behaviour Research and Therapy, Vol. 41 No. 7, pp. 795-807.

Basabe, N. and Ros, M. (2005), "Cultural dimensions and social behavior correlates: individualismcollectivism and power distance", International Review of Social Psychology, Vol. 18 No. 1, pp. 189-225.

Sociocultural behavioral traits 
JHASS 3,5

Bentall, R.P., Lloyd, A., Bennett, K., McKay, R., Mason, L., Murphy, J., McBride, O., Hartman, T.K., Gibson-Miller, J., Levita, L. and Martinez, A.P. (2021), "Pandemic buying: testing a psychological model of over-purchasing and panic buying using data from the United Kingdom and the republic of Ireland during the early phase of the covid-19 pandemic", PloS One, Vol. 16 No. 1, p. e0246339.

Black, S., Bloom, D.E., Kaslow, D.C., Pecetta, S. and Rappuoli, R. (2020), "Transforming vaccine development", Seminars in Immunology, Elsevier, 101413.

Bond, M.H. and Lun, V.M.C. (2014), "Citizen-making: the role of national goals for socializing children", Social Science Research, Vol. 44, pp. 75-85.

Borak, J. (2020), “Airborne transmission of COVID19”, Occupational Medicine, Vol. 70 No 5, pp 297-299.

Boyd, M.J., Wilson, N. and Nelson, C. (2020), "Validation analysis of global health security index (ghsi) scores 2019", BMJ Global Health, Vol. 5 No. 10, p. e003276.

Cameron, J.E. and Nuzzo, J.B. (2020), The Global Health Security Index 2020, Nuclear Threat Initiative, available at: www.ghsindex.org/

Chaudhuri, S., Basu, S., Kabi, P., Unni, V.R. and Saha, A. (2020), "Modeling the role of respiratory droplets in covid-19 type pandemics", Physics of Fluids, Vol. 32 No. 6, p. 63309.

Dalglish, S.L. (2020), "Covid-19 gives the lie to global health expertise”, The Lancet, Vol. 395 No. 10231, p. 1189.

Duong, D.M., Le, V.T. and Ha, B.T.T. (2020), "covid 19? controlling the covid-19 pandemic in vietnam: lessons from a limited resource country”, Asia Pacific Journal of Public Health, Vol. 32 No. 4, pp. 161-162.

Durante, R., Guiso, L. and Gulino, G. (2021), “Asocial capital: civic culture and social distancing during covid-19", Journal of Public Economics, Vol. 194, p. 104342.

Elbaum, R. (2020), Dec. 14 Coronavirus Updates: First Federally Approved Vaccine Administered, NBC News, available at: www.nbcnews.com/news/us-news/blog/covid-19-coronavirus-vaccinehospitals-warp-speed-n1251068

Galbadage, T., Peterson, B.M. and Gunasekera, R.S. (2020), "Does covid-19 spread through droplets alone?", Frontiers in Public Health, Vol. 8, p. 163.

Glenwick, D.S. and Jason, L.A. (1984), "Behavioral community psychology: an introduction to the special issue", Journal of Community Psychology, Vol. 12 No. 2, pp. 103-112.

Gadarian, S.K., Goodman, S.W. and Pepinsky, T.B. (2021), "Partisanship, health behavior, and policy attitudes in the early stages of the COVID-19 pandemic", Plos One, Vol. 16 No. 4, p. e0249596.

He, L., He, C., Reynolds, T.L., Bai, Q., Huang, Y., Li, C., Zheng, K. and Chen, Y. (2021), "Why do people oppose mask wearing? A comprehensive analysis of us Tweets during the Covid-19 pandemic", Journal of the American Medical Informatics Association, Vol. 28 No. 7, pp. 1564-1573.

Hearne, B.N. and Niño, M.D. (2021), "Understanding how race, ethnicity, and gender shape maskwearing adherence during the covid-19 pandemic: evidence from the covid impact survey", Journal of Racial and Ethnic Health Disparities, Vol. 2021, pp. 1-8.

Hofstede, G. (1984), [Dataset] Culture's Consequences: International Differences in Work-Related Values, Vol. 5, Sage, pp. 13-252.

Hofstede, G. (1986), "Cultural differences in teaching and learning", International Journal of Intercultural Relations, Vol. 10 No. 3, pp. 301-320.

Hofstede, G. (1991), Cultures and Organizations: Software of the Mind, McGraw-Hill, New York, Vol. 1.

Hofstede, G. (1996), "Gender stereotypes and partner preferences of asian women in masculine and feminine cultures", Journal of Cross-Cultural Psychology, Vol. 27 No. 5, pp. 533-546.

Hofstede, G. (2009), Geert Hofstede Cultural Dimensions, Taylor Training.

Hofstede, G. (2011), "Dimensionalizing cultures: the hofstede model in context", Online Readings in Psychology and Culture, Vol. 2 No. 1, pp. 2307-0919. 
Hofstede, G. (2016), "Culture's consequences: comparing values, behaviors, institutions, and organizations across nations", Collegiate Aviation Review, Vol. 34 No. 2, p. 108.

Hofstede, G., Hofstede, G.J. and Minkov, M. (2005), Cultures and Organizations: Software of the Mind, McGraw-Hill, New York, Vol. 2.

Sociocultural

behavioral

traits

Honigsbaum, M. (2009), “Pandemic”, The Lancet, Vol. 373 No. 9679, p. 1939.

Howard, J., Huang, A., Li, Z., Tufekci, Z., Zdimal, V., van der Westhuizen, H.M., von Delft, A., Price, A., Fridman, L., Tang, L.H. and Tang, V. (2021), "An evidence review of face masks against covid19”, Proceedings of the National Academy of Sciences, Vol. 118 No. 4, pp. 1-12.

House, R.J., Hanges, P.J., Javidan, M., Dorfman, P.W. and Gupta, V. (Eds) (2004), “Culture, leadership, and organizations", The GLOBE Study of 62 Societies, Sage publications, pp. 1-28.

Hubbard, J. (2020), Coronavirus (Covid-19) Update: December 14, 2020, Federal Drug Agency (FDA), available at: www.fda.gov/news-events/pressannouncements/coronavirus-covid-19-updatedecember-14-2020

Huynh, T.L.D. (2020), "Does culture matter social distancing under the covid-19 pandemic?", Safety Science, Vol. 130, p. 104872.

Iancu, D. and Badea, D. (2020), "Empirical analysis of the influence of culture in managerial processes based on the hofstede model", International Conference Knowledge-Based Organization, Sciendo, Vol. 26, pp. 205-210.

Inglehart, R. and Baker, W.E. (2000), "Modernization, cultural change, and the persistence of traditional values", American Sociological Review, Vol. 65 No. 1, pp. 19-51.

Jason, L.A., Glenwick, D.S. and Moritsugu, J. (2021), "Behavioral methods in community settings: a neglected or a vital force?”, Behavior and Social Issues, 2021, pp. 1-10.

Jay, V. and Paulo, B. (2020), "National identity predicts public health support, during a global pandemic", pre-print from psyarxiv.

Kapros, E. (2019), "Towards addressing the limitations of educational policy based on international large-scale assessment data with castoriadean magmas", Innovations in Big Data Mining and Embedded Knowledge, Springer, pp. 61-81.

Karaivanov, A., Lu, S.E., Shigeoka, H., Chen, C. and Pamplona, S. (2021), "Face masks, public policies and slowing the spread of COVID-19: evidence from Canada", Journal of Health Economics, Vol. 78, 102475 .

Lenartowicz, T. and Roth, K. (2001), "Does subculture within a country matter? A cross-cultural study of motivational domains and business performance in Brazil", Journal of International Business Studies, Vol. 32 No. 2, pp. 305-325.

Leung, K., Bond, M.H., de Carrasquel, S.R., Muñoz, C., Hernández, M., Murakami, F., Yamaguchi, S., Bierbrauer, G. and Singelis, T.M. (2002), "Social axioms: the search for universal dimensions of general beliefs about how the world functions", Journal of Cross-Cultural Psychology, Vol. 33 No. 3, pp. 286-302.

Mahrous, A.A. (2011), "Antecedents of privacy concerns and their online actual purchase consequences: a cross-country comparison", International Journal of Electronic Marketing and Retailing, Vol. 4 No. 4, pp. 248-269.

Margraf, J., Brailovskaia, J. and Schneider, S. (2020), "Behavioral measures to fight covid-19: an 8-country study of perceived usefulness, adherence and their predictors", Plos One, Vol. 15 No. 12, p. e0243523.

Mazey, S. and Richardson, J. (2020), "Lesson-drawing from New Zealand and covid-19: the need for anticipatory policy making", The Political Quarterly, Vol. 91 No. 3, pp. 561-570.

McInnes, C. and Lee, K. (2006), "Health, security and foreign policy", Review of International Studies, Vol. 32 No.1, pp. 5-23.

Minkov, M. (2007), What Makes us Different and Similar: A New Interpretation of the World Values Survey and Other Cross-Cultural Data, Klasika i Stil Publishing House Sofia, Bulgaria. 


\section{JHASS 3,5}

Minkov, M., Hofstede, G. and Hofstede, G.J. (2016), “Allemaal andersdenkenden: omgaan met cultuurverschillen", Business Contact, pp. 1-3.

Minkov, M. and Kaasa, A. (2021), "A test of the revised minkov-hofstede model of culture: mirror images of subjective and objective culture across nations and the 50 US states", Cross-Cultural Research, 2021, 10693971211014468.

Morens, D.M., Folkers, G.K. and Fauci, A.S. (2009), "What is a pandemic?”, The Journal of Infectious Diseases, Vol. 200 No. 7, pp. 1018-1021.

Murray, C.J. and Frenk, J. (2008), "Health metrics and evaluation: strengthening the science", The Lancet, Vol. 371 No. 9619, pp. 1191-1199.

Nikolov, P., Pape, A., Tonguc, O. and Williams, C. (2020), "Predictors of social distancing and maskwearing behavior: panel survey in seven us states", pre-print from arXiv, 2009.13103.

Nuzzo, J.B., Bell, J.A. and Cameron, E.E. (2020), "Suboptimal us response to covid-19 despite robust capabilities and resources”, Jama, Vol. 324 No. 14, pp. 1391-1392.

Oppenheim, B., Gallivan, M., Madhav, N.K., Brown, N., Serhiyenko, V., Wolfe, N.D. and Ayscue, P. (2019), "Assessing global preparedness for the next pandemic: development and application of an epidemic preparedness index", BMJ Global Health, Vol. 4 No. 1.

Palmer, C.L. and Peterson, R.D. (2020), "Toxic mask-ulinity: the link between masculine toughness and affective reactions to mask wearing in the covid-19 era", Politics and Gender, Vol. 16 No. 4, pp. 1044-1051.

Razavi, A., Erondu, N. and Okereke, E. (2020), "The global health security index: what value does it add?", BMJ Global Health, Vol. 5 No. 4, p. e002477.

Ritchie, H. (2020), Coronavirus Source Data, European Center for Disease Prevention and Control, available at: https://ourworldindata.org/coronavirus-source-data

Rodrigues, U.M. and Xu, J. (2020), "Covid 19 Regulation of covid-19 fake news infodemic in China and India”, Media International Australia, Vol. 177 No. 1, pp. 125-131.

Rushton, S. (2011), "Global health security: security for whom? security from what?", Political Studies, Vol. 59 No. 4, pp. 779-796.

Rushton, S. and Youde, J. (2014), Routledge Handbook of Global Health Security, Routledge, pp. 5-81.

Setti, L., Passarini, F., De Gennaro, G., Barbieri, P., Perrone, M.G., Borelli, M., Palmisani, J., Di Gilio, A., Piscitelli, P. and Miani, A. (2020), "Airborne transmission route of COVID-19: why 2 meters/6 feet of inter-personal distance could not be enough", International Journal of Environmental Research and Public Health, Vol. 17 No. 8, p. 2932.

Shanthakumar, S.G., Seetharam, A. and Ramesh, A. (2020), "Understanding the socio-economic disruption in the united states during Covid-19's early days", pre-print from arXiv, 2004.05451.

Soofi, M., Najafi, F. and Karami-Matin, B. (2020), "Using insights from behavioral economics to mitigate the spread of covid-19", Applied Health Economics and Health Policy, Vol. 18 No. 3, pp. 345-350.

Stankov, L., Lee, J. and Van de Vijver, F.J. (2014), "Two dimensions of psychological country-level differences: conservatism/liberalism and harshness/softness", Learning and Individual Differences, Vol. 30, pp. 22-33.

Steinhauser, Z.K.D. (2018), "Culture as a factor influencing creativity", Central and Eastern Europe in the Changing Business Environment, p. 152.

Triandis, H.C. (2018), Individualism and Collectivism, Routledge, pp. 19-68.

Tung, R.L. (2008), "The cross-cultural research imperative: the need to balance cross-national and intranational diversity", Journal of International Business Studies, Vol. 39 No. 1, pp. 41-46.

van Buuren, S., Kelley, D.E., Mas, J.F., Rahlf, T., Murray, S., Leemis, L., Dayal, V., Sun, C. and Kohl, M. (2018), "Flexible imputation of missing data", Language, p. 579.

van der Linden, S., Roozenbeek, J. and Compton, J. (2020), "Inoculating against fake news about covid19", Frontiers in Psychology, Vol. 11, p. 2928. 
Xu, B., Gutierrez, B., Mekaru, S., Sewalk, K., Goodwin, L., Loskill, A., Cohn, E.L., Hswen, Y., Hill, S.C., Cobo, M.M. and Zarebski, A.E. (2020), "Epidemiological data from the COVID-19 outbreak, realtime case information", Scientific Data, Vol. 7 No. 1, pp. 1-6.

World Health Organization (2020), "Getting your workplace ready for COVID-19: how COVID-19 spreads, 19 March 2020 (No. WHO/2019-nCov/workplace/2020.2)”, World Health Organization, pp. 1-8.

\section{Appendix}

The codes, data and resources for this project could be found at the github page https://github.com/ cja5553/socio-cultural-behavioral-traits-and-covid19

\section{Corresponding author}

Charles Alba can be contacted at: cja5553@psu.edu

For instructions on how to order reprints of this article, please visit our website: 